\title{
Révolution et redistribution des richesses dans les campagnes : mythe ou réalité ?
}

Revolution and Redistribution of Wealth in the Countryside: Myth or Reality?

\section{Gérard Béaur}

\section{(2) OpenEdition \\ 1 Journals}

\section{Édition électronique}

URL : https://journals.openedition.org/ahrf/11151

DOI : 10.4000/ahrf.11151

ISSN : 1952-403X

Éditeur :

Armand Colin, Société des études robespierristes

\section{Édition imprimée}

Date de publication : 1 juin 2008

Pagination : 209-239

ISBN : 978-2200-92514-7

ISSN : 0003-4436

Référence électronique

Gérard Béaur, "Révolution et redistribution des richesses dans les campagnes : mythe ou réalité ? ", Annales historiques de la Révolution française [En ligne], 352 | avril-juin 2008, mis en ligne le 01 juin 2011, consulté le 23 avril 2022. URL : http://journals.openedition.org/ahrf/11151 ; DOI : https:// doi.org/10.4000/ahrf.11151 


\title{
RÉVOLUTION ET REDISTRIBUTION DES RICHESSES DANS LES CAMPAGNES : MYTHE OU RÉALITÉ ?
}

Gérard BÉAUR

\begin{abstract}
Les mesures prises par les révolutionnaires et les conditions auxquelles ils furent confrontés provoquèrent des redistributions de richesses brutales et inédites dans un milieu rural habituellement considéré comme immuable. Certaines de ces redistributions sont bien repérées, d'autres sont nettement plus discrètes et cet article a pour projet de les répertorier et d'en mesurer l'ampleur. II montre que les changements instillés dans les campagnes furent fort inégaux dans l'espace, moins spectaculaires qu'on pouvait l'escompter, mais que leur accumulation produisit une société nouvelle, dont les membres connurent des sorts différents selon la place qu'on leur assigne dans les processus de redistribution.
\end{abstract}

Mots-clés : biens nationaux, communaux, prélèvements, successions, crédit, profits et revenus salariaux.

La Révolution française fut aussi une révolution à l'intérieur du corps social. Énoncer cette banalité n'est sans doute pas inutile à l'heure où aller vendre son veau à la foire est devenu un acte politique. Mais défendre ce point de vue, c'est déjà soulever une foule de problèmes ardus. Le premier est de se demander quel est le contenu de ce bouleversement ? On pourra argumenter longtemps et facilement autour de la relève d'une noblesse épuisée par une bourgeoisie triomphante. Certes, mais encore ? Qu'en est-il à la campagne ? Comment penser le changement social en un lieu où rôde avec constance le mythe de la routine, de la sclérose, de l'immobilisme ? Comment envisager des reclassements 
profonds dans un milieu où les choses bougent lentement $?^{1}$ À dire vrai, on ne manque pas de travaux de grande qualité qui ont tenté de repérer, de jauger, de mesurer l'ampleur des changements qui ont pu secouer la société rurale au cours de la décennie révolutionnaire ou dans sa continuité. On ne manque pas non plus de travaux de grande valeur qui ont marqué, soupesé, évalué les répercussions de la Révolution sur la paysannerie ${ }^{2}$. Il en existe beaucoup, mais bien moins nombreux sont ceux qui ont pris la question sous l'angle des redistributions opérées à la faveur des réformes engagées par les révolutionnaires, ou à la lueur des situations contextuelles dans lesquelles se trouvaient prises les différentes strates qui composaient la société villageoise. C'est à partir de ces recherches, dont beaucoup sont récentes, que l'on voudrait ici esquisser un bilan des gains obtenus et des pertes subies par les différents protagonistes installés à la campagne.

Avant d'aller plus loin et de reprendre ce dossier, on éludera plus ou moins un sujet annexe qui mériterait à lui seul des développements beaucoup plus longs : celui de la nature de ces redistributions. S'agit-il de redistributions pures dans un système productif inchangé ou de redistributions entre gagnants/gagnants dans une économie en expansion, ou encore de redistributions perdants/perdants dans une économie contractée? On sait que le débat fait rage pour savoir si la Révolution a été une catastrophe économique ou un tremplin vers une croissance ultérieure ${ }^{3}$. Il n'est pas moins vif pour décider dans le premier cas si elle a été une rupture dans une économie euphorique jusqu'au bout ou bien si elle prolonge une phase de dépression. Il n'est pas inexistant pour argumenter autour de l'idée qu'elle ait pu être un redémarrage dans une économie languissante ou une simple parenthèse dans une période de longue d'expansion ${ }^{4}$. Cette interrogation n'est pas au centre de nos préoccupations, elle a déjà fait l'objet de quelques commentaires antérieurs et elle mériterait de trop longs développements. Pour ces trois raisons, on n'en traitera donc pas réellement dans ce texte, même si les constats opérés au fil de l'exposé conduiront fatalement à y revenir brièvement dans la conclusion.

(1) Gérard BÉAUR, Histoire agraire de la France au XVIII siècle. Inerties et changements dans les campagnes françaises à la fin de l'époque moderne (jusqu'en 1815), Paris, SEDES, 2000.

(2) La production scientifique est trop considérable pour que l'on tente ici une approche bibliographique.

(3) Numéro spécial de la Revue Économique, 40-6, novembre 1989 : «Révolution de 1789. Guerres et Croissance économique ».

(4) Cf. l'introduction de Gérard BÉaur et Philippe Minard, dans Gérard BÉaur, Philippe Minard, Alexandra LaClau (éd.), Atlas de la Révolution française, vol. 10 : Économie, Paris, Éditions de l'EHESS, 1997. 
Redistributions, donc, quelle qu'en soit la portée. Redistributions autour de la terre, bien balisées et mieux appréciées aujourd'hui, comme celles qui résultent des ventes de biens nationaux, des partages de communaux et de la nouvelle donne sur le marché de la terre ; redistributions autour des prélèvements qui proviennent des profondes réformes introduites par les Assemblées, tant par la remise en cause radicale de la ponction seigneuriale et décimale que par la transformation subie par le régime fiscal ; redistributions, enfin, autour des revenus rentiers, salariaux ou des profits des exploitants provoquées par la dépréciation de l'assignat aussi bien que par la nouvelle configuration des marchés des fermes et du travail, autour de la dette laminée par la chute de la monnaie-papier, autour des héritages en raison des profonds aménagements du système successoral. La liste est-elle exhaustive?

\section{La terre}

\section{Les biens nationaux : main basse sur le foncier?}

On sait quelle débauche d'énergie a été dépensée par les historiens autour de ce que l'on a fini par considérer comme «l'événement le plus important de la Révolution $»^{5}$. La mise à l'encan des biens du clergé, puis des émigrés, suspects, condamnés... a déclenché un transfert de propriété qui a paru inouï aux contemporains comme aux historiens. Elle a provoqué depuis les premiers travaux de Loutchiski ${ }^{6}$, et cela pendant un siècle, une avalanche d'études minutieuses qui avaient pour objet les ventes passés en un village, en un canton, en un arrondissement, un département et dont il était très difficile de sortir une synthèse, tant les résultats paraissaient disparates. Quelle avait été l'ampleur de cette expropriation ? Pendant très longtemps, on a hésité. Aujourd'hui on sait.

Dès les années 1930, Lecarpentier avançait une première fourchette oscillant entre 6 et $10 \%$ pour les biens du clergé qui fut reprise par Georges Lefebvre dans un article longtemps décisif et qui garde encore

(5) Bernard Bodinier, Éric Teyssier, L'Événement le plus important de la Révolution française : la vente des biens nationaux (1769-1867) en France et dans les territoires annexés, Paris, Éditions du CTHS, 2000.

(6) Ivan Vasilevitch Loutchisky, « De la petite propriété en France et de la vente des biens nationaux », Revue historique, 1895, 4, p. 71-122 ; Idem, La petite propriété en France avant la Révolution française et la vente des biens nationaux, Paris, H. CHAMPION, 1897, rééd. par Bernard Bodinier, Éric Teyssier, Propriété paysanne et vente des biens nationaux pendant la Révolution française, Paris, Éditions du CTHS, 1999 ; Idem, La propriété paysanne en France à la veille de la Révolution (principalement en Limousin), Paris, H. Champion, 1912. 
toute sa pertinence 7 . À ce compte, les biens de seconde origine représentant peut-être les $2 / 3$ des biens de première origine, auraient compté pour 4 à $7 \%$. Donc au total 10 à $17 \%$ des terres auraient changé de mains à la suite des mesures révolutionnaires. Le remarquable travail de synthèse conduit par Bernard Bodinier et Éric Teyssier permet d'affirmer de manière certaine qu'on doit se situer dans le bas de la fourchette, soit un peu moins de $6 \%$ pour les biens ecclésiastiques, un peu moins de $10 \%$ au total ${ }^{8}$.

C'est à la fois beaucoup et peu. Que quelque 5 millions d'ha passent ainsi brutalement de main en main ce n'est certes pas une petite affaire. Mais que moins de $10 \%$ des terres soient concernées, ce n'est pas si exceptionnel qu'on pourrait le penser de prime abord. Les redistributions antérieures dans l'Allemagne de la Contre-Réforme ou les mises en ventes lors de la desamortizacion espagnole furent sans aucun doute tout aussi spectaculaires. Pourtant, il est permis de penser qu'elles n'eurent pas le même retentissement au niveau européen. On pourrait argumenter que la mise en adjudication des biens du clergé représentait une initiative stupéfiante et la confiscation des biens des ennemis de la Révolution, en contravention totale avec la sublimation du droit de propriété par la Constituante, une mesure inédite. Il n'en est rien. Les biens du clergé avaient à plusieurs reprises subis des amputations ponctuelles lors des guerres de religion par exemple. Il y avait belle lurette que les esprits éclairés réclamaient la prise de possession des biens du clergé. C'était notamment le cas des letrados espagnols, qui attendaient de cette réforme une plus grande efficacité de l'agriculture'. Les biens des Jésuites avaient déjà été saisis au moment de la grande offensive contre l'ordre au milieu du siècle. De son côté, Joseph II n'avait pas attendu la Révolution française pour s'attaquer aux biens de mainmorte dans les Pays-Bas autrichiens ${ }^{10}$. En forçant le trait, on pourrait prétendre, comme je l'ai déjà fait ailleurs, que nulle part l'affaire des biens nationaux n'avait eu aussi peu d'importance et que nulle part on n'en avait autant

(7) Georges LefeBvRe, « Les recherches relatives à la répartition de la propriété et de l'exploitation foncières à la fin de l'Ancien Régime », Revue d'histoire moderne, 1928, III, p. 103-130 (rééd. dans Études sur la Révolution française, 1954, p. 201-222, et 1963, p. 279-306). p. $155-188$

(8) Bernard Bodinier, Éric Teyssier, L'Événement le plus important..., op. cit.,

(9) Pablo F. Luna, La reforma de la sociedad y la defensa de los derechos del propietario, según G.M. de Jovellanos, a finales del antiguo régimen, Oviedo, 2006.

(10) François Antoine, La vente des biens nationaux dans le département de la Dyle, Bruxelles, Archives générales du Royaume, 1997. 
parlé $^{11}$. Oui, mais voilà, la Révolution française inaugura un mouvement radical et l'exporta avec les armées révolutionnaires aussi bien qu'avec la diffusion des nouvelles idées. Elle posa ainsi avec acuité la question de la légitimité des possessions ecclésiastiques et en même temps celle de l'inviolabilité des biens des « ennemis de la Patrie ». Enfin, elle mit brutalement à la disposition des acquéreurs potentiels, jusque-là réfrénés dans leur appétit foncier, des biens-fonds particulièrement convoités.

Reste à se demander qui profita de l'aubaine et s'empara des biens ainsi aliénés. Les historiens ont multiplié les tentatives pour essayer de savoir qui avait bien pu se porter acquéreur. Il semblerait que la paysannerie n'ait recueilli que des miettes avec les biens de première origine, notamment en 1791 lorsque les biens furent mis en adjudication en bloc. Certes, il ne manque pas d'exemples où les paysans se coalisèrent, bloquèrent les enchères, découragèrent les concurrents de la ville ${ }^{12}$, mais ils ne purent s'adjuger que quelque 20 à $30 \%$ des biens ${ }^{13}$. À partir de l'an II, la vente par lots changea la donne avant les désastreuses mises en vente du Directoire et les paysans purent sauter sur l'occasion. Au total, ils s'adjugèrent peut-être un tiers des propriétés mises en vente, soit peut-être 1,5 million d'ha, ce qui est considérable et leur procura un gain de l'ordre de $3 \%$ du sol. Si l'on admet qu'ils détenaient de 40 à $45 \%$ du sol à la veille de la Révolution, ils auraient vu leur part passer à 43 ou $48 \%$. C'est appréciable, ce n'est pas un raz-de-marée. Ils auraient accru leur part foncière de l'ordre de $10 \%$, tandis que les propriétaires profitaient au maximum de la dépossession du clergé. Ce n'était pas une révolution foncière mais un véritable chambardement.

Encore ignorons-nous, cependant, comment cette redistribution foncière agit sur le corps social. Qui étaient ces acheteurs ? Des sans-terre qui devenaient tout à coup micro-propriétaires ? Des micro-propriétaires qui obtinrent une croissance plus ou moins forte de la taille de leur patrimoine? Ou de gros propriétaires qui soit acquirent des biens supplémentaires à la marge, soit amplifièrent considérablement une assise foncière déjà solide ?

En fait, derrière les moyennes, les inégalités furent flagrantes. Les villages dans lesquels le clergé possédait peu de choses furent de bien

(11) Gérard BÉAUR, « L'histoire économique de la Révolution n'est pas terminée », dans Martine LAPIED, Christine PEYRARD (dir.), La Révolution française au carrefour des recherches, Aixen-Provence, Publications de l'Université de Provence, 2003, p. 21-44.

(12) Association Histoire et Archives drômoises et Archives départementales de la Drôme, Que le bonheur habite dans les chaumières. La vente des biens nationaux dans la Drôme, Valence, 1994.

(13) Bernard Bodinier, Éric TEYssier, L'événement le plus important..., op. cit., p. 215-228. 
faibles vainqueurs et il en fut de même lorsque les seigneurs s'abstinrent d'émigrer. Mais quelles perspectives alléchantes ouvraient l'antique domination foncière d'un couvent ou d'un chapitre, l'émigration d'un ou plusieurs nobles gros propriétaires! Dans tel village, ce fut la ruée, dans tel autre, on se contenta de grappiller le peu qui était offert. Tout le monde ne pouvait pas habiter dans le district de Cambrai avec un évêque qui d'un seul coup offrait à toutes les convoitises environ $40 \%$ du sol, tout le monde ne pouvait pas se précipiter sur les 8500 ha du chapitre cathédral de Chartres ${ }^{14}$. Il fallait bien plus souvent se contenter de la mise en vente de $1 \%$ du sol, parfois 2 ou 3 au maximum. La mise en vente des biens nationaux introduisit ainsi une profonde césure entre les ruraux dont l'origine était purement aléatoire. Ce n'était pas la seule. Là où une couche de paysans riches pouvaient se porter adjudicataires, les gains furent importants, là où la société rurale était composée de pauvres hères, ils furent bien maigres. Là, où une petite ville proche abritait des bourgeois aux féroces appétits, la concurrence fut trop forte, là où nul bourgeois ne se trouvait à pied d'œuvre, les perspectives étaient beaucoup plus encourageantes ${ }^{15}$.

À ce jeu, il est probable que la région parisienne fut le lieu des meilleures affaires, car le clergé y possédait de vastes fermes et la noblesse détenait de larges parties du sol : il suffisait qu'elle veuille bien émigrer, ce qu'elle fit fréquemment. Les gros fermiers tirèrent le meilleur parti d'une conjoncture aussi avantageuse malgré la pression de la bourgeoisie (et de la noblesse) parisienne. Ils furent nombreux à se porter acquéreurs des terres ainsi mises à leur disposition, à commencer par la ferme qu'ils mettaient jusque-là en valeur contre un fermage ${ }^{16}$. Rétrospectivement, tout paraît d'une simplicité biblique et on sait qu'ils firent une excellente affaire puisque avec la dépréciation de l'assignat, cette terre leur coûta fort peu. En réalité, ils durent certainement longtemps hésiter. Car, contrairement à ce que rapporte une légende tenace, les biens nationaux ne furent

(14) Michel Vovelle, « Un des plus grands chapitres de France à la fin de l'Ancien Régime : le Chapitre cathédral de Chartres ", Actes du $85^{\mathrm{e}}$ Congrès national des Sociétés Savantes, ChambéryAnnecy, 1960, Paris, 1961, repris dans Ville et campagne au XVIII siècle (Chartres et la Beauce), Paris, Éditions sociales, 1980, p. 169-207.

(15) C'était déjà l'hypothèse de Paul Bors, Paysans de l'Ouest. Des structures économiques et sociales aux options politiques depuis l'époque révolutionnaire dans la Sarthe, Le Mans, Imp. M. Vilaire, 1960, Paris-La Haye, éd. EPHE-Mouton, 1960.

(16) Jean-Marc Moriceau, « Une nouvelle donne économique ? Les adjudications de fermes autour de Paris (Districts de Corbeil, Gonesse, Meaux et Versailles) », Paris et Île-de-France, Mémoires, tome 41, 1990, p. 409-528. 
nullement bradés au cours des premières années. L'empressement fut grand et il fallut payer le prix. Quand Antoine-François Chartier, le fermier du Plessis-Gassot, se résolut à acheter la ferme qu'il exploitait jusque-là à bail, il dut certainement passer quelques nuits difficiles. Il s'endettait en effet pour de nombreuses années et immobilisait ainsi durablement de l'argent dont il avait sans doute besoin ailleurs. Mais pouvait-il laisser passer cette occasion unique d'être maître chez lui et de s'emparer d'une terre qu'il considérait comme sienne puisque sa famille la cultivait depuis si longtemps et qui représentait le fondement de son statut social ? Pouvait-il prendre le risque de se retrouver fermier d'un autre laboureur, voire d'être mis à la porte par un confrère soucieux de mettre lui-même en valeur la terre ainsi durement acquise ? Pour difficile qu'elle fût, la décision s'imposait d'elle-même ${ }^{17}$. Nul ne pouvait prévoir la formidable dégringolade de l'assignat qui allait lui permettre comme à tant d'autres de se dégager en payant en « monnaie de singe ».

\section{Les droits collectifs : un coup d'épée dans l'eau?}

Mais ce n'était pas tout. Les petits paysans avaient encore la faculté de l'emporter lors de la session de rattrapage que constituaient les redistributions de communaux. Ils pouvaient enfin essayer de conquérir des parcelles à la faveur des décisions prises par la Révolution ${ }^{18}$.

En effet, tout au long du XVIII ${ }^{\mathrm{e}}$ siècle, les réformateurs s'en étaient pris avec violence aux biens et aux pratiques collectifs. Agronomes, économistes et hommes politiques ne cessaient de militer pour la suppression de ce qui apparaissait comme une monstruosité, comme un frein à l'agriculture. Tandis que les droits d'usages empêchaient la clôture des terres et les innovations agronomiques, les biens communaux représentaient un scandaleux gaspillage et il convenait d'y mettre fin $^{19}$. En les partageant, on obtiendrait leur mise en culture et donc on accroîtrait l'espace cultivé,

(17) Jean-Marc Moriceau, Gilles Postel-Vinay, Ferme, entreprise, famille. Grande exploitation et changements agricoles : les Chartier (XVII $-X I X^{e}$ siècles), Paris, Éditions de l'EHESS, 1992, p. $56-58$ et $155-162$.

(18) On citera Marc Bцoch, même si son long article sur l'individualisme agraire évoque très peu les communaux et s'attache essentiellement aux droits d'usage : « La lutte pour l'individualisme agraire dans la France du XVIII ${ }^{\mathrm{e}}$ siècle », Annales d'Histoire Économique et Sociale, II, juillet 1930, p. 329-381 et octobre 1930, p. 511-543. Sur la distinction droits collectifs/propriété collective, Gérard BÉAUR, « En un débat douteux. Les communaux, quels enjeux dans la France des XVIII-XIX siècles ? », Revue d'histoire moderne \& contemporaine, 53-1, 2006, p. 89-114.

(19) Nadine VIVIER, Propriété collective et identité communale : les Biens communaux en France (1750-1914), Paris, Presses de la Sorbonne, 1998, p. 15. 
on permettrait un essor de la production agricole et on résoudrait les tensions rémanentes qui empoisonnaient l'approvisionnement en céréales. De leur côté, les seigneurs exploitant le sentiment ambiant, s'employaient à en accaparer une partie quitte à en attribuer le solde à la communauté rurale, par les triages et cantonnements qui suscitaient des conflits inexpiables avec les paysans ${ }^{20}$. Procès, sabotages en tout genre rythmaient un processus difficile, tissé de combats judiciaires, avec des avancées et des reculs de part et d'autre ${ }^{21}$.

Pourtant le gouvernement monarchique temporisait. Ne risquait-on pas d'acculer les pauvres à la misère en les privant de ces ressources modestes mais décisives et de les pousser à déserter les campagnes pour la ville? N'allait-on pas accentuer la question sociale et occasionner des troubles extrêmement périlleux ? Une vague d'édits de partages promulgués par la couronne à partir de la fin des années 1760 entendit mettre un terme à l'indécision et prétendit faire disparaître les terres collectives ${ }^{22}$. Il s'agissait d'attribuer un tiers des biens au seigneur et d'allouer le solde aux exploitants sous forme de lots inaliénables, viagers, mais la procédure restait facultative et elle était soumise à l'accord de la communauté. Des partages se produisirent effectivement en Flandre aux dépens des lambeaux de communaux qui n'avaient pas encore été appropriés, et tout aussi bien en Artois et en Lorraine, ponctuellement dans la région parisienne (Soissonnais, Picardie, Île-de-France) et en Alsace. Mais partout ailleurs les oppositions l'emportèrent. Opposition de la communauté hostile à l'idée de perdre un tiers des biens en jouissance commune, opposition de la part des laboureurs et des seigneurs qui entendaient bien conserver leurs droits d'accès sur ces pacages. Indécision des pauvres eux-mêmes, pris dans une terrible contradiction : dans l'ensemble avides d'arrondir leurs lopins, mais soucieux de ne pas perdre les droits d'usages lorsqu'ils en bénéficiaient sur les terres vaines et vagues ${ }^{23}$. Le cas de l'Alsace est exemplaire à cet égard ${ }^{24}$.

(20) Florence GAUthIER, La voie paysanne dans la Révolution française, l'exemple picard, Paris, Maspero, 1977, p. 99-102.

(21) Jean-Jacques Clère, Les paysans de la Haute-Marne et la Révolution française. Recherches sur les structures foncières de la communauté villageoise, Paris, Éditions du CTHS, 1988, p. 131-146.

(22) Nadine VIVIER, Propriété collective et identité communale..., op. cit., p. 96.

(23) Gérard BÉAUR, « En un débat douteux... », art. cit., et « Über eine mehrdeutige Diskussion. Gemeinheitsteilungen, Eigentumsgewinnung und Agrarfortschritt (Frankreich, 18. und 19. Jahrhundert) », Jahrbuch für Wirtschaftsgeschichte, 2000-2, p. 33-43.

(24) Jean-Michel Boehler, Une société rurale en milieu rhénan : la paysannerie de la plaine d'Alsace (1648-1789), Strasbourg, Presses Universitaires de Strasbourg, 1994, p. 1264-1284. 
Dès le début de la Révolution, une forte pression s'exerça sur la Constituante pour qu'elle revienne sur les expropriations subies et engage une politique de partage. Si le triage fut rapidement proscrit, il fallut attendre mars 1790 pour que l'Assemblée décide que les communautés pouvaient se pourvoir devant les tribunaux pendant 5 ans pour récupérer les biens arrachés par cette voie pendant les 30 années précédentes; en août 1792, la loi attribua par principe les terres vaines et vagues aux communautés et leur conféra le droit de réclamer tous les biens extorqués " par l'effet de la puissance féodale », et enfin la loi de juin 1793 mit un terme aux atermoiements du gouvernement ${ }^{25}$. Des sentences arbitrales rendues par des experts permettent aux communautés de récupérer les biens qui leur ont été confisqués. C'était souvent entériner les récupérations sauvages qui avaient succédé aux procédures judiciaires jusque-là souvent infructueuses et qui eurent dorénavant de larges chances d'aboutir. C'est par centaines que les communes entreprennent de reprendre les communaux perdus et ce sont des milliers et des milliers d'ha qui sont ainsi rétrocédés aux communautés ${ }^{26}$. La portée de cette restitution fut cependant réduite par les dispositions prises après Thermidor et surtout pendant le Directoire. Elles autorisèrent, en effet, l'appel contre les décisions qui avaient renvoyé les communautés en possession de leurs biens et qui provoquèrent un nombre important d'annulations de sentences arbitrales $^{27}$.

Dans le même temps, la Convention montagnarde donna enfin satisfaction aux paysans en accordant le partage des communaux. Il s'agissait d'un partage en pleine propriété, par tête, avec interdiction de revente pendant 10 ans, et soumis à l'accord d'un tiers des membres de la communauté. Là encore, il convient de s'interroger sur la portée de l'opération. Pour certains historiens, elle fut considérable, pour d'autres, elle eut peu d'effets. Le bilan est d'autant plus délicat que cette loi ne fut qu'une courte parenthèse et que rapidement les gouvernements revinrent en arrière. Dès prairial an IV, la loi est suspendue. Elle l'est définitivement et les partages sont dorénavant interdits, avant que la loi de ventôse an XII ne confie aux conseils de préfecture le soin d'arbitrer les contestations qui peuvent s'exprimer. C'est dans la plus grande confusion que certains partages sont maintenus et d'autres annulés, en fonction des vices de

(25) Nadine VIVIER, Propriété collective..., op. cit., p. 97-102 et 115-124.

(26) Jean-Jacques CLère, Les paysans de la Haute-Marne..., op. cit., p. 217-233.

(27) Ibid., p. 229-233. 
procédure, ou de l'absence d'application ou encore de l'humeur du préfet $^{28}$.

Encore une fois, les inégalités géographiques sont considérables. Ici, il y avait peu de communaux, là ils étaient très étendus. Ici, la volonté de partage était vive, là elle était inexistante. Pour simplifier, les partages furent peu nombreux dans les montagnes et dans l'Ouest, soit parce que les communaux étaient indispensables à l'économie rurale, soit parce qu'ils étaient rares, soit encore parce que le droit de propriété était mal assuré (en Bretagne). En revanche, ils furent nombreux au nord de Paris, et dans le Nord-Est, là où la tension était déjà vive sur cette question sous l'Ancien Régime, soit parce que la pression des pauvres était forte, soit parce que les laboureurs estimaient en avoir moins besoin ${ }^{29}$. Localement, la redistribution fut donc tantôt assez large, tantôt inexistante. En règle générale, sauf exceptions notables, elle ne fut intense que dans les zones où il ne subsistait déjà que des lambeaux de communaux. Les rétrocessions furent nombreuses dans les zones où les tensions étaient demeurées vives à l'intérieur même de la communauté rurale, dans le Nord-Est notamment, elles furent faibles là où les communautés restèrent coites.

Ainsi, la redistribution fut-elle beaucoup plus limitée qu'elle aurait pu l'être. Pour plusieurs raisons. La principale fut que les communautés eurent peu de temps pour se décider et que de nombreuses annulations furent prononcées. La seconde était que les communautés demeuraient extrêmement divisées et que leurs membres eux-mêmes étaient sans doute indécis. Pourtant, il est certain que certains micro-propriétaires purent profiter de l'aubaine et qu'ils furent parfois nombreux à s'emparer de biens mis gratuitement à leur disposition.

\section{Le marché ordinaire : ruée sur le foncier}

En réalité, et Jean Sentou avait le premier attiré notre attention sur ce fait capital : les ventes de biens nationaux n'ont représenté qu'une part minoritaire des biens en circulation, même en ne prenant en considération que la seule décennie révolutionnaire. En 10 ans, autour de Toulouse, le volume du marché extraordinaire n'atteignait que la moitié du volume des biens qui transitaient par le marché que j'ai appelé « ordinaire $»^{30}$. Et

(28) Nadine Vivier, Propriété collective..., op. cit., p. 189-194.

(29) Ibid., p. 57-61.

(30) Jean SENTOU, La fortune immobilière des Toulousains et la Révolution française, Paris, Bibl. nationale, Commission d'Histoire économique et sociale de la Révolution française, Mémoires et Documents, XXIV, 1970, p. 23-34. 
encore nous nous situons peut-être ici dans une hypothèse haute. Mais il n'empêche. Regardons le cas du Domfrontais. En un quart de siècle, la part des biens nationaux ne correspond qu'à $1 / 6^{\mathrm{e}}$ des biens qui transitent par le marché ${ }^{31}$. Raisonnons autrement. Des indices concordants tendent à accréditer l'idée que la terre « tournait » à une vitesse de l'ordre de $1 \%$ par an avant la Révolution, sans doute un peu plus vite après $1789^{32}$. On peut donc raisonnablement inférer que plus de $10 \%$ des biens-fonds sont passés par le marché ordinaire pendant les 10 dernières années du XVIII ${ }^{\mathrm{e}}$ siècle. Autrement dit, au moins l'équivalent de ce que représentait la masse des biens nationaux.

En fait, avec la vente des biens nationaux, on en reste à la première phase de la redistribution foncière instillée par la Révolution. Les spéculateurs se chargèrent parfois de débiter les fermes en lots pour les revendre avec bénéfices et là les paysans tinrent peut-être leur revanche même s'il est bien difficile de mesurer ce qu'ils arrachèrent ainsi par la suite. Ce que l'on sait, c'est que sur le marché ordinaire qui incluait les reventes de morceaux de biens nationaux, les ruraux, et plus particulièrement les cultivateurs ou les marchands ruraux, figurent partout, une fois encore, comme les principaux bénéficiaires des mutations en cours. Il en fut ainsi à Domfront, à Amboise ou à Vernon ${ }^{33}$.

En s'acharnant peut-être sur l'accessoire, en restant hypnotisés par ce qui se jouait sur le marché des biens nationaux, les historiens ont pendant longtemps négligé l'essentiel ${ }^{34}$. Le marché ordinaire a été débloqué par la Révolution. Il l'a été par la libération de la terre, par la suppression des entraves et des droits de mutation qui en gênaient la circulation, par les effets induits de la mise sur le marché des biens mis à la disposition de la nation. Un peu partout, à Lizy-sur-Ourcq comme on l'avait montré dès 1988, mais aussi à Domfront, à Amboise, à Vernon, le marché foncier

(31) Jean-Claude MARTIN, La terre en révolution. Biens nationaux et marché foncier dans le Domfrontais 1789-1830, Le pays Bas-Normand, 1989, n²-3-4, p. 246.

(32) Gérard BÉAUR, Le marché foncier à la veille de la Révolution. Les mouvements de propriété beaucerons dans les régions de Maintenon et de Janville de 1761 à 1790, Paris, Éditions de l'EHESS, 1984, p. 55 ; Anne Jollet, Terre et société en Révolution. Approche du lien social dans la région d'Amboise, Paris, Éditions du CTHS, 2000, p. 237 ; Fabrice BoudJAABA, La circulation des biens-fonds dans la région de Vernon (1750-1830). Le patrimoine des familles entre logiques du marché et contraintes du cycle de vie, thèse Université de Paris IV, 2005, p. 127.

(33) Jean-Claude Martin, La terre en révolution..., op. cit, p. 241-243; Anne Jollet, Terre et société..., op. cit., p. 378-396 ; Fabrice BoudJAABA, La circulation des biens-fonds..., thèse citée, p. $179-184$.

(34) Gérard BÉAUR, « La Révolution et la question agraire: Vieux problèmes et perspectives nouvelles (note critique) », Annales ESC, 48-1, 1993, p. 135-145. 
s'est emballé ${ }^{35}$. À Lizy, le nombre de ventes triple entre 1780 et 1810 , à Amboise, c'est à un doublement du nombre de transactions que l'on assiste. Tant et si bien que je me suis demandé si 1791 ne correspondait pas à l'an I du marché foncier ${ }^{36}$.

À dire vrai, il semble qu'un premier frémissement était déjà apparu au milieu du siècle, puis que les premières mises en ventes de domaines s'étaient multipliées après $1770^{37}$. Néanmoins, il faut bien convenir qu'à partir de 1791, le nombre de ventes explose littéralement. Et cette accélération de la circulation du foncier constitue une rupture absolument décisive dont on aurait tort de sous-estimer la portée. À quoi faut-il en attribuer la responsabilité ? À un effet mécanique de la mise sur le marché de terres écartées du marché foncier et qui se mettent à « tourner » très vite ? À la suppression des contraintes légales (droits de retrait) et financières qui pesaient sur le marché (lods et ventes...) ? À la désorganisation du système de crédit ? À l'instabilité économique et financière qui accentue le caractère de valeur-refuge de la terre ? Aux effets des autres redistributions de richesse et de revenus qui entraînent une valse des propriétés?

Cet intense turn-over de la propriété allait forcément avoir des conséquences considérables au cours du XIX ${ }^{\mathrm{e}}$ siècle et progressivement démythifier le foncier dans les esprits. Pour l'heure, il contribua à un nouveau transfert de propriété. Comme sous l'Ancien Régime, les gagnants furent les paysans et plus particulièrement les laboureurs mais aussi les marchands. En Beauce, on avait déjà fait ce constat à la veille de la Révolution ${ }^{38}$. À Domfront, les paysans gagnent quelque 500000 francs de biens-fonds en un quart de siècle, les marchands (sans doute pour partie des paysans aisés) environ 1 million de francs ${ }^{39}$. À Amboise, en 1811 , ce sont les vignerons qui progressent le plus, trois fois plus que les laboureurs, renouant ainsi avec la progression qui était la leur au tout

(35) Gérard BÉAUR, « Révolution et transmission de la propriété : le marché foncier ordinaire (Lizy-sur-Ourcq et Bar-sur-Seine entre 1780 et 1810) », dans La Révolution française et le monde rural, Paris, éditions du CTHS, 1989, p. 271-286. Jean-Claude MARTIN, La terre en révolution..., op. cit, p. 220-224 ; Anne Jollet, Terre et société..., op. cit., p. 223-233 ; Fabrice BoudJAABA, La circulation des biens-fonds..., thèse citée p. 112-118.

(36) Gérard BÉAuR « 1789. L'an I du marché foncier ? », Études foncières (Revue de l'ADEF), n 41, décembre 1988, p. 36-39.

(37) Cette animation croissante est fréquemment perceptible en feuilletant les registres du centième denier.

(38) Gérard BÉAur, Le marché foncier à la veille de la Révolution..., op. cit., p. 190-198, particulièrement graphique p. 194.

(39) Jean-Claude MARTIN, La terre en révolution..., op. cit., p. 227. 
début de la Révolution, en 1791. Leur bénéfice foncier s'inscrirait ainsi à 500000 francs en 25 ans, les hissant ainsi au niveau des paysans de Domfront, toutes choses étant égales par ailleurs ${ }^{40}$. N'exagérons pas l'ampleur de ce transfert. Pour Domfront, les paysans obtiennent un excédent de $1 \%$ de l'espace considéré, les marchands de $2 \%$. Ce n'est pas énorme, ce n'est pas dérisoire non plus.

Par le canal des deux voire trois marchés complémentaires, une redistribution de la terre se produisit au profit d'une fraction de la paysannerie, avec d'énormes différences sociales et géographiques. Les ventes de biens nationaux ont constitué un transfert de biens-fonds assez considérable, assurément moins formidable qu'on ne l'a dit, mais elles furent consenties avec des conditions financières inouïes. Pendant ce temps d'autres mouvements de propriété, indépendants ou non de cette opération, complétaient le brassage de cartes qui intervint ainsi sur le plan foncier via le marché. C'est donc à nouveau comme avant la Révolution d'un grignotage qu'il s'agit et non d'un transport social massif de biensfonds. Mais il ne faut pas pour autant minimiser les incidences de cette lente poussée foncière.

\section{Les prélèvements}

\section{Les droits seigneuriaux : une si longue attente?}

Tout le monde sait que c'est dans la nuit du 4 Août que la Constituante décide d'abolir le système féodal. Si le principe est simple, l'application est compliquée. L'Assemblée entreprend dès le lendemain de cette nuit d'ivresse de sauver la propriété dont elle s'apprête à proclamer le caractère sacré. Pour y parvenir, elle établit une distinction qu'elle veut radicale entre les droits censés être issus d'une usurpation de la puissance publique et donc supprimés sans condition et les droits produits par un accord à défaut d'un contrat et qui sont la contrepartie légitime d'une concession de fonds. La loi du 15 mars 1790 précise ce qui doit être racheté car correspondant à un droit de propriété exercé par le seigneur et ce qui est doit être aboli sans condition. La mainmorte, détruite. La taille, abandonnée. Les droits de garenne, de chasse éradiqués. Les banalités, les péages abrogés. Les justices supprimées. En revanche, les rentes foncières, y compris les champarts, terrages et agrières maintenues jusqu'à rachat et les lods et ventes conservés jusqu'à

(40) Anne Jollet, Terre et société..., op. cit., p. 394-395. 
indemnisation ${ }^{41}$. Ce subtil compromis conduisait à des distinctions conflictuelles et surtout laissait les paysans abasourdis. Pour eux, tous ces droits étaient illégitimes et ils entendaient bien ne plus les payer.

Dès 1789 , les droits ne sont plus acquittés. L'exemple de la Normandie montre que les recettes seigneuriales s'effondrent ${ }^{42}$. Les lods et ventes sont anéantis. Ce n'est pas pour autant que les rachats prolifèrent. Ils sont rarissimes là où on a cherché à les repérer. Ni dans la Sarthe, ni dans la Haute-Vienne, ni dans le Doubs, ni en Seine-Inférieure, ni en Charente-Maritime, les quittances de rachat ne sont légion ${ }^{43}$. En juin, puis en août 1792, la Convention décide que les droits seigneuriaux sont purement et simplement supprimés, sauf production d'un titre par le bénéficiaire et, finalement, en juillet 1793, elle les abolit purement et simplement. Seules subsistent les rentes perpétuelles issues des baux à rente, ce qui ne laissera pas de poser des problèmes de délimitation assez ardus.

Certes, cette mesure n'est pas absolument novatrice. Depuis longtemps, ces droits sont attaqués, critiqués, vilipendés, comme vexatoires, injustifiés et surtout comme entraves au progrès. Dans la Savoie du royaume de Piémont-Sardaigne, ils ont été également supprimés, mais la grande différence, et là la Révolution innove, c'est que cette fois aucune indemnisation n'est versée aux anciens détenteurs ${ }^{44}$. Il s'agit donc d'un transfert de richesse net qui allège les charges des tenanciers et diminue d'autant les ressources des seigneurs. En cela il s'agit d'une réforme audacieuse, qui est largement le produit des circonstances certes, mais qui est inédite et qui sera peu reprise ailleurs.

Quelle est l'importance de cette redistribution et qui en profite? La comptabilisation de ce que chacun a gagné et perdu est difficile. On ne

(41) Jean Gallet, Seigneurs et Paysans en France, 1600 à 1793, Rennes, Éditions OuestFrance, 1999, p. 254.

(42) Guy Lemarchand, La fin du féodalisme dans le pays de Caux. Conjoncture économique et démographique et structure sociale dans une région de grande culture de la crise du XVII siècle à la stabilisation de la Révolution (1640-1795), Paris, Éditions du CTHS, 1989, p. 425 .

(43) Philippe Goujard, L'abolition de la féodalité dans le Pays de Bray (1789-1793), Paris, Bibl. nationale, 1979, et «L'abolition de la féodalité dans le district de Neuchâtel (Seine-Inférieure) », dans Albert Soвоul (dir.), Contributions à l'histoire paysanne de la révolution française, Paris, Éditions sociales, 1977, p. 353-375 ; Jean-Noël Luc, « Le rachat des droits féodaux dans le département de la Charente-Inférieure (1789-1793) », dans ibidem, p. 309-352.

(44) Jean Nicolas, « La fin du régime féodal en Savoie (1771-1792) », dans L'abolition de la féodalité dans le monde occidental, Colloque de Toulouse 1968, Paris, CNRS, 1971, p. 27-108. 
tentera pas de dresser une nouvelle fois le répertoire des droits dûs par les censitaires. La litanie est longue et en partie trompeuse, et cela pour deux raisons au moins. Si certains droits sont très lourds, il en existe une kyrielle qui sont surtout symboliques. Pire, la liste est fallacieuse car elle donne à penser que les paysans sont assujettis à une foule de droits. Or, il n'en est rien. La diversité est la règle et chacun ne doit acquitter qu'un éventail de droits réduit. Bien mieux, il ne manque pas d'historiens pour rappeler à juste raison que beaucoup de ces droits sont circonstanciels. Celui qui n'achète pas de terres ne paie pas de lods et ventes, celui qui n'a pas de grain à moudre, ni de vin à presser ou de pain à cuire n'est redevable d'aucune banalité, celui qui n'a pas de terre ne règle ni cens ni champart, et l'on pourrait multiplier les exemples ${ }^{45}$. La seigneurie n'est pas seulement une structure d'exploitation mais aussi une structure de services. Pour être vrai, l'argument n'en est pas moins un peu forcé car à moins d'être dans le dénuement le plus absolu, nul n'échappe absolument au seigneur.

Tout le monde ou presque a donc gagné quelque chose. Le profit à attendre est évidemment proportionnel à la lourdeur du système féodal et seigneurial subi jusque-là. Or, on sait que ce poids est extrêmement variable. Il existe des régions à féodalité dure et d'autres à " féodalité molle ». Pesante, sans doute en Bourgogne, en Auvergne, en Bretagne, légère en Île-de-France, en Normandie, dans le Bas-Maine, en Champagne ${ }^{46}$. Les uns arguent que la seigneurie emportait moins de $2 \% \mathrm{du}$ revenu, et même parfois moins de $1 \%$, les autres trouvent des taux de prélèvements extrêmement lourds, plus de $6 \%$ du produit net et même quelque $10 \%$. Il faudrait étalonner tous ces chiffres. En réalité, c'est

(45) Annie AntoIne, « La seigneurie, la terre et les paysans, XVII ${ }^{\mathrm{e}}-\mathrm{XVIII}{ }^{\mathrm{e}}$ siècles », dans $L a$ Terre et les Paysans, France et Grande-Bretagne, XVII -XVIII ${ }^{e}$ siècles, numéro spécial du Bulletin de la Société d'Histoire Moderne \& Contemporaine, 1999, 1-2, p. 15-33 et « La seigneurie en France à la fin de l'Ancien Régime. État des connaissances et nouvelles perspectives de recherches », dans Gérard Béaur, Christophe Duhamelle, Reiner Prass, Jürgen Schlumbohm (eds), Les Sociétés rurales en Allemagne et en France (XVIII ${ }^{e}-X I X^{e}$ siècles), Rennes, Association d'Histoire des Sociétés Rurales, Collection Bibliothèque d'Histoire Rurale 8, p. 47-64 (trad. française de l'ouvrage édité par les mêmes auteurs, Göttingen, Vandenhoeck \& Ruprecht, 2003).

(46) Pierre de SAInt JACOB, Les Paysans de la Bourgogne du nord au dernier siècle de l'Ancien Régime, Paris, Les Belles-Lettres, 1960, éd. Rennes, Association d'Histoire des Sociétés Rurales, 1995, p. 107-139 ; Michel LEYMARIE, « Les redevances foncières seigneuriales en HauteAuvergne », Annales Historiques de la Révolution Française, n 193, 1968, p. 299-380 ; Henri SÉE, Les classes rurales en Bretagne du XVI siècle à la Révolution, Paris, V. Giard et E. Brière, 1906, p. 178-205 ; Guy Lemarchand, La fin du féodalisme..., op cit, p. 291-296 ; Annie Antoine, Fiefs et villages du Bas-Maine au XVIII siècle, Mayenne, Éditions Régionales de 1'Ouest, 1994, p. 213-239; Jean-Jacques Clère, Les paysans de la Haute-Marne..., op. cit., p. 119-125. 
d'une seigneurie à l'autre, selon la gestion plus ou moins rigoureuse du seigneur, et même à l'intérieur de la seigneurie d'une tenure à l'autre, que le prélèvement variait et que le gain octroyé par la Révolution est plus ou moins important. Ici, pour les paysans, l'économie est considérable, là elle est minime.

Pour les paysans, disions-nous ? Pas forcément, de nombreuses tenures appartiennent à des propriétaires qui habitent en ville. Certains droits pénalisent plus directement les bourgeois. Ainsi en est-il des lods et ventes puisqu'ils participent, à l'échelle individuelle s'entend, plus activement au marché foncier. Ainsi en est-il des droits sur la terre, puisque, à l'échelle individuelle encore une fois, ils sont plus largement pourvus. Il reste que ce sont les paysans qui collectivement sont les principaux bénéficiaires. En ont-ils conscience ? Certes, mais, en réalité, ils ne s'agit en aucun cas pour eux d'un « cadeau ». Il y a bien longtemps qu'ils considéraient ces droits comme des extorsions, qu'ils se regardaient comme des propriétaires à part entière. Leur peu d'empressement à procéder au rachat prouve qu'ils n'ont jamais pensé sérieusement qu'ils devaient indemniser les seigneurs ${ }^{47}$. À cet égard, le contraste est net entre les charges seigneuriales instantanément oubliées, bien avant d'être officiellement éteintes, et les loyers payés « rubis sur l'ongle », jamais contestés, car jugés légitimes. Quand bien même il serait erroné d'en exagérer l'importance, il reste que ce changement constituait un allégement de charges qui n'avait rien de négligeable.

\section{La dîme : un coup gagnant?}

Un autre prélèvement subit le même sort mais avec plus de célérité que les droits seigneuriaux, c'est le prélèvement décimal. Dès la nuit du 4 Août la dîme est supprimée. Elle n'est plus justifiée puisque l'État entend prendre en charge l'enseignement, l'assistance et les frais du culte. Certes, elle doit théoriquement être levée jusqu'en 1790, le temps que la réforme fiscale produise ses effets, mais cette concession ne trompe personne. Déjà objet de contestations incessantes, déjà victime de fraudes innombrables, déjà sujette à des grèves de plus en plus fréquentes, semble-t-il,

(47) Gérard BÉAUR, « Les rapports de propriété en France sous l’Ancien Régime et dans la Révolution. Transmission et circulation de la terre dans les campagnes françaises du XVI ${ }^{\mathrm{e}}$ au XIX siècle ", dans Nadine VIVIER (éd.), Ruralité française et britannique, XIII ${ }^{e} X X^{e}$ siècles. Approches comparées, Rennes, Presses universitaires de Rennes, 2005, p. 187-200. 
la dîme sombre très vite ${ }^{48}$. Bien avant le 4 Août la rumeur affirme qu'elle a été abolie. C'est qu'elle paraît anachronique, pesant sur le produit net, handicapant l'innovation culturale, mettant en danger le produit des récoltes en attendant d'être prélevée sur le champ. D'un trait de plume, on vient de mettre fin au prélèvement le plus universel qui soit.

Il ne s'agit pas d'une mince affaire. La dîme n'emportait, en fait, que rarement $10 \%$ du produit brut, même si l'ordre de grandeur n'a rien d'aberrant. En fait, les taux sont extrêmement inégaux d'une province à l'autre, dans la même province d'une paroisse à l'autre, à l'intérieur de la même paroisse, selon les règles en vigueur pour chaque décimateur. $\mathrm{Si}$, dans le Bordelais, le prélèvement à la treizième gerbe $(7,5 \%)$ est le plus courant, en Limagne il n'est d'ordinaire qu'à la vingtième gerbe (5\%), mais il peut monter jusqu'à $25 \%$ et descendre jusqu'à $2,5 \%$, comme en Touraine. En Haute-Marne, il oscille du onzième au treizième (7,7 à $9 \%$ environ), il peut se hisser au septième en Bretagne ou en Lorraine (environ $14 \%)^{49}$. Il peut enfin être dérisoire en Beauce ou en Poitou et il convient de rappeler que ce prélèvement est nul sur les produits du jardin proche de la maison, comme il l'est sur certaines cultures nouvelles ou spécifiques : les fourrages artificiels la plupart du temps, les légumes et les raves quelquefois, les pommes de terre et le maïs fréquemment ${ }^{50}$. On pourrait multiplier les exemples qui tendraient à prouver que si tous les exploitants sont gagnants, leur bénéfice est extrêmement variable.

(48) Jean Nicolas, «L'enjeu décimal dans l'espace rural savoyard », dans Joseph Goy, Emmanuel Le Roy Ladurie (dir.), Prestations paysannes, dîmes, rente foncière et mouvement de la production agricole à l'époque moderne, Paris-La Haye-New York, Mouton, 1982, p. 663-691 ; Georges FrÊCHE, « Dîmes et production agricole : remarques méthodologiques à propos de la région toulousaine », dans Joseph Goy, Emmanuel LE Roy LADURIE (dir.), Les fluctuations du produit de la dîme. Conjoncture décimale et domaniale de la fin du Moyen Âge au XVIII siècle, Paris-La Haye, Mouton, 1972, p. 214-244 ; Colette Merlin, Ceux des villages. La société rurale dans la " Petite Montagne " jurassienne à la veille de la Révolution, Cahiers d'Études comtoises, 52, Annales littéraires de l'université de Besançon, 523, 1994, p. 133-140 ; Marie-Thérèse LoRCIN, " La fraude des décimables : mouvement long ou mouvement court? », dans Joseph Goy, Emmanuel Le Roy LAdURIE (dir.), Prestations paysannes, dîmes..., op. cit., p. 599-606.

(49) Gérard AubIn, La seigneurie en Bordelais d'après la pratique notariale (1715-1789), Rouen, Publications de l'Université de Rouen, 1989, p. 270-273; Abel PoitrinEAu, La vie rurale en Basse-Auvergne au XVIII siècle (1726-1789), Paris, PUF, 1965, p. 351-352 ; Brigitte MaILlaRD, Les campagnes de Touraine au XVIII siècle. Structures agraires et économie rurale, Rennes, Presses Universitaires de Rennes, 1998, p. 388-400 ; Guy LEMARCHAND, La fin du féodalisme dans le pays de Caux..., op. cit., p. 34 ; Jean-Jacques Clère, Les paysans de la Haute-Marne..., op. cit., p. 116 ; Henri SÉE, Les classes rurales en Bretagne, op. cit., p. 163-169 ; Jean-Claude FARCY, Les paysans beaucerons au XIX siècle, Chartres, Société archéologique d'Eure-et-Loir, 1989, p. 107-108.

(50) Abel Poitrineau, La vie rurale en Basse-Auvergne..., op. cit., p. 352 ; Jean-Jacques Clère, Les paysans de la Haute-Marne..., op. cit., p. 115 ; Georges FrêCHE, « Dîmes et production agricole... », art. cit. ; Guy Lemarchand, La fin du féodalisme..., op. cit., p. 34. 
Quelle importance revêt globalement cet allégement de charge ? En Normandie, on estime que 7 à $21 \%$ du revenu serait ainsi épargné, en Bordelais quelque 12,3\%, en Haute-Auvergne environ 12,6\% du produit net, en Bourgogne entre le quart et le cinquième, et là encore on pourrait multiplier les exemples ${ }^{51}$. Globalement, on a estimé que le prélèvement devait atteindre 110 à 120 millions de livres avant la Révolution, le quart de l'impôt environ. L'économie réalisée par les paysans était donc substantielle, pas très loin d'équivaloir au montant d'une rente qui aurait été assise sur l'ensemble du capital foncier du pays.

Mais les paysans ont-ils réellement profité de cette disparition? Rien n'est moins sûr car les révolutionnaires avaient laissé toute latitude aux propriétaires pour incorporer l'équivalent de ce prélèvement décimal dans les baux. Si tel a été le cas, cela signifie que la suppression de la dîme a profité aux propriétaires et non aux paysans. Il est difficile de se former un jugement là-dessus d'autant que les situations ont été probablement très disparates selon les rapports (de forces notamment) qui sévissaient entre propriétaires et fermiers. Mais que recouvre la hausse des loyers bien analysée par D. Zolla il y a un siècle ? Une croissance du produit brut ou une confiscation de la dîme par les propriétaires qui aurait mécaniquement fait progresser le niveau de la rente ? On peut hésiter ${ }^{52}$. Que les propriétaires aient fréquemment tenté de profiter de la situation, on l'imagine aisément. Qu'ils y aient réussi parfaitement et durablement est beaucoup plus douteux. En fait, il est même parfaitement loisible de plaider l'inverse. On pourrait en effet tout aussi bien admettre que dans un contexte aussi troublé, il aurait été, disons maladroit, d'augmenter la pression sur les fermiers. Ou alors il faudrait supposer que la situation de ces derniers n'était pas aussi dramatique qu'on essaie généralement de le faire croire et que donc la progression des fermages avait peu à voir avec « l'effet-dîme ».

Tout le monde gagna certainement dans cette affaire, la question pendante est de savoir à qui a profité le plus cette manne tant attendue. Il n'y eut que deux perdants : le clergé, on l'a compris facilement, mais aussi les fermiers receveurs, on y reviendra plus loin.

(51) Guy Lemarchand, La fin du féodalisme..., op. cit., p. 328 sq ; Gérard Aubin, La seigneurie en Bordelais..., op. cit., p. 272 ; Pierre de SAINT JACOB, Les Paysans de la Bourgogne du nord..., op. cit., p. 133; Michel Leymarie, « Les redevances foncières seigneuriales... », art. cit.

(52) Daniel Zolla, «Les variations du revenu et du prix des terres en France aux XVII et XVIII' siècles ", Annales de l'École Libre des Sciences Politiques, 1893, p. 299-326, 439-461, 686705, et 1894 , p. 194-216 et 417-438. 
L'impôt : des miraculés de la pause fiscale?

Les cahiers de doléances étaient, on le sait, emplis de revendications anti-fiscales. La contestation de tous les impôts était très répandue ce qui tombait bien mal dans le climat d'endettement qui avait accompagné la convocation des États généraux. Le maintien des privilèges fiscaux, écornés à maintes reprises, mais jamais abolis par la monarchie était impraticable. Tout le problème était de savoir comment on allait procéder. D'emblée, l'Assemblée supprima tous les impôts indirects. Elle se privait certes d'une rentrée d'argent abondante mais comment conserver cette forme d'imposition dans l'atmosphère d'exécration qui entourait cette forme de prélèvement? L'Assemblée ne se fit d'ailleurs pas violence pour en finir avec les indirects, tant empreinte d'idées physiocratiques elle entendait bien faire porter la nouvelle contribution sur le seul capital foncier (y compris accompagnée par la contribution mobilière), avec une entorse : une modeste patente.

La suppression du privilège fiscal entraînait une extension de l'assiette de l'impôt. Le cas de Janvry dans l'Essonne démontre que l'inclusion des anciens exemptés sur le rôle de 1790 entraîna mécaniquement une hausse de $122 \%$ de la masse imposable ${ }^{53}$. On comprend que la nouvelle contribution aurait rapporté plus du double de l'impôt d'Ancien Régime si la Constituante n'avait pas stabilisé le prélèvement au niveau antérieur. Ne disposant d'aucun élément pour apprécier le revenu national et les capacités contributives des citoyens, l'Assemblée dut en effet partir des prélèvements d'Ancien Régime et plus particulièrement du vingtième pour établir les bases du nouvel impôt ${ }^{54}$. En visant trop bas le niveau de ponction fiscale, malgré les avertissements de Lavoisier, on se préparait des lendemains budgétaires difficiles, mais le pire était encore à venir pour le gouvernement et le meilleur pour les contribuables.

Ainsi, localement, grâce à la mansuétude des Constituants, la charge fiscale des habitants de Janvry chuta-t-elle de moitié en moyenne. Bon début pour les contribuables de cette paroisse, probablement très satisfaits de cet aménagement fiscal, et déjà déchargés, on l'a dit, de tout prélèvement indirect. Mais tout le monde n'était pas logé à l'enseigne de

(53) Mireille Touzery, « La dernière taille. Abolition des privilèges et technique fiscale d'après les rôles de Janvry pour les six derniers mois de 1789 et pour 1790 », Histoire \& Mesure, XII, 1-2, 1997, p. 93-142.

(54) Robert Schnerb, La péréquation fiscale de l'Assemblée Constituante, 1790-1791, Clermont Ferrand, Imprimerie Générale de Bussac, 1930. 
Janvry ${ }^{55}$. Dans beaucoup de paroisses, on dut regretter de ne pas abriter d'anciens privilégiés désormais assujettis au nouvel impôt et qui par leurs propriétés contribuaient désormais à élargir l'assiette, et donc à faire diminuer le montant payé par chacun. Mais ce n'était pas tout. La nouvelle répartition conservait les inégalités d'Ancien Régime. Elle perpétuait, malgré les correctifs introduits, les injustices entre provinces ${ }^{56}$. Il y avait beaucoup de gagnants parmi les contribuables mais certains gagnaient plus que d'autres.

De toute manière, les choses tournèrent de telle façon que tous ne purent que se féliciter du nouveau cours des événements. En fait, dès le début de la Révolution, le rendement de l'impôt s'effondra. Les redevables s'acquittèrent mal et avec retard comme sous l'Ancien Régime, mais rapidement le phénomène changea de nature. Ils ne payèrent quasiment plus rien, profitant du désordre général et surtout de la dépréciation de l'assignat. Le gouvernement eut beau exiger un paiement en partie en grains à la fin de l'an III au plus fort de la chute du papier-monnaie, il est clair que les impôts ne rentrent plus guère. En l'an II, les contributions perçues par le nouveau régime équivalent à $37 \%$ des seuls impôts directs de la fin de la monarchie, en l'an III on en est à $16 \%$, chiffres qu'il faut diviser par 2 pour mesurer l'évolution de la charge fiscale totale. Ce n'est qu'en l'an VII et VIII que l'on retrouve le niveau de la ponction directe pré-révolutionnaire et qu'en 1806 que la ponction totale atteint le niveau global de $1789^{57}$.

Bien sûr l'appétit fiscal de l'État se réveille avec l'Empire. Le meilleur rendement de la foncière et de la mobilière est évident. Fini le paiement en «monnaie de singe ». Mais surtout la renaissance et la croissance des impositions indirectes avec la création des droits réunis sont fulgurants. On constate un alourdissement de la charge fiscale pas toujours bien vécu par les redevables. En fait, compte tenu de la hausse des prix qui l'accompagne et de la progression de l'assiette par l'imposition des privilégiés, on peut estimer que les ruraux restent largement gagnants quand bien même les propriétaires s'emploient à faire retomber les contributions sur leurs fermiers. En réalité, les contribuables, si l'on peut encore les appeler ainsi, s'étaient habitués à ne rien payer et ils n'avaient pas fait la Révolution pour continuer à être imposés comme auparavant.

(55) Mireille TOUZERY, « La dernière taille... », art. cit.

(56) Robert Schnerb, La péréquation fiscale..., op. cit.

(57) Tim J. A. Le Goff, Donald M. G. Sutherland, « La Révolution française et l'économie rurale », Histoire \& Mesure, 1999, XIV, 1/2, p. 79-120. 
On comprend mieux pourquoi les révolutionnaires les avaient tant ménagés et avaient supporté, voire favorisé une telle pause fiscale. Pour faire face à des dépenses extravagantes apportées par la guerre, il n'y avait pas d'autre solution que de faire fonctionner la planche à billets et de faire payer les pays conquis (un grand merci à nos amis belges, néerlandais et surtout italiens qui avaient suppléé les carences du fisc). Mais cela ne pouvait avoir qu'un temps.

Heureux Français qui ne paient pratiquement aucun impôt pendant près de $10 \mathrm{ans}^{58}$. De quoi ridiculiser tous les néo-libéraux acharnés à réduire la facture fiscale quelles qu'en soient les conséquences. Il est très difficile de mesurer le formidable transfert de richesse qui s'ensuit et d'en apprécier les effets macro-économiques, mais il n'est pas difficile d'en suspecter les incidences sur le niveau de vie des contribuables et de conclure qu'il s'agit d'une formidable redistribution.

\section{Les revenus}

L'exploitation. Les fermiers dans la tourmente, les salariés sur la sellette?

L'abolition de la dîme et des droits seigneuriaux eut des effets ambigus sur les profits des fermiers. D'un côté, comme on l'a noté, elle les libéra d'un prélèvement désagréable et leur laissa un produit net supérieur à celui qui leur revenait jusque-là, si tant est que les propriétaires n'en profitèrent pas pour pousser les loyers à la hausse naturellement. D'un autre côté, elle les priva des profits qu'ils faisaient traditionnellement par l'affermage de ces prélèvements. Plus de jeu possible sur les stocks et de spéculation sur les denrées. On conçoit que les laboureurs durent vivre ces changements avec des sentiments mêlés.

Il est assez difficile de mesurer l'évolution du prélèvement rentier. Il s'accrut, autant du moins qu' on puisse en juger. Tim Le Goff et Donald Sutherland ont validé les intuitions de Zolla et adopté au terme d'une enquête rigoureuse une progression de 12 à $25 \%$ entre 1789 et 1799 en valeur nominale, largement occasionnée, selon eux, par la hausse des prix et la confiscation de la dîme ${ }^{59}$. La rente aurait donc stagné en valeur réelle,

(58) T. J. Sargent, François R. Velde, « Macroeconomic Features of the French Revolution », Journal of Political Economy, 103-3, 1995, p. 474-518.

(59) Daniel Zolla, « Les variations du revenu et du prix des terres... », art. cit. ; Tim J. A. Le Goff, Donald M. G. Sutherland, « La Révolution française et l'économie rurale... », art. cit. 
voire régressé. Que faut-il en conclure ? Les interprétations les plus communes conduisent à se débattre dans une contradiction. Si la rente progresse, elle confisque le surplus des fermiers et nuit au progrès agricole. Si elle ne progresse pas, cela veut dire que la production stagne voire régresse. Loterie étonnante, avec laquelle on ne peut que perdre et en aucun cas gagner.

Il me semble qu'il convient de prendre le problème autrement en se situant dans une autre temporalité. Il n'est pas exact, et Philip Hoffman l'a bien montré, que les fluctuations de la Productivité Totale des Facteurs sont efficaces dans la courte durée. Il en est de même de la rente. L'instrument (PTF ou rente) n'est valide que dans la moyenne durée ${ }^{60}$. Or, nous savons que la rente fut lente à accompagner la prospérité retrouvée au milieu du XVIII ${ }^{e}$ siècle. Elle doubla brutalement en valeur nominale au cours des années 1770 . Nul n'affirmera que la production agricole s'est envolée si soudainement ${ }^{61}$. En réalité, les fermiers ont accepté des loyers en hausse par excès de confiance et de concurrence. Cette hausse fit en effet celle de la RF I, celle acquittée par les gros exploitants, longtemps différée contrairement à ce qui était arrivée à la RF II, celle des petits exploitants ${ }^{62}$. Dans les années 1780, l'euphorie étant passée, la rente amorça un repli qui traduisait l'incapacité des fermiers à maintenir des taux aussi hauts et une nouvelle mobilisation contre les prétentions excessives des propriétaires ${ }^{63}$. À notre sens, la stagnation des années 1790 n'est que la prolongation d'une tendance antérieure, accentuée autant par des difficultés réelles que par un climat politique plus favorable aux exploitants. Autrement dit, j'aurais tendance à interpréter le nouveau cours de la rente comme le reflet d'une amélioration du sort des laboureurs ou comme le produit de leur résistance.

Mais ce n'est pas tout. La rente aurait grimpé en valeur nominale, avant de chuter sous le Consulat, et de ne repartir à la hausse que pendant $1^{\prime} E m p i r{ }^{64}$. On voit immédiatement le problème. Comment expliquer que

(60) Philip T. Hoffman, Growth in a Traditional Society. The French Countryside, 14501815, Princeton, Princeton University Press, 1996, p. 193-198.

(61) Gérard BÉAUR, « Le mouvement annuel de la rente foncière chartraine (1760-1780) », dans Joseph Goy, Emmanuel Le Roy Ladurie (dir.), Prestations paysannes, dimes..., op. cit., p. 491-501.

(62) Gilles Postel-Vinay, La rente foncière dans le capitalisme agricole. Analyse de la voie " classique » du développement du capitalisme dans l'agriculture à partir de l'exemple du Soissonnais, Paris, Maspero, 1974, p. 32 et 36.

(63) Gérard BÉAUR, Le marché foncier à la veille de la Révolution..., op. cit., p. 262-276.

(64) Tim J. A. Le Goff, Donald M. G. Sutherland, « La Révolution française et l'économie rurale... », art. cit. 
la chute ait eu lieu après et non pas pendant la Révolution ? La position qui consiste à dire que la production agricole était moins forte après le Directoire que pendant la décennie révolutionnaire est difficilement tenable si la période révolutionnaire fut si difficile. On a en effet peu d'arguments pour soutenir que la production agricole accusait une hausse sensible à l'issue de la Révolution. La comparaison an IX/1789 ne permet de proposer qu'une croissance modeste ${ }^{65}$. Il est donc clair que les fermiers ont su négocier des prélèvements rentiers en baisse.

Au même moment, les gros fermiers subissaient de plein fouet les réquisitions et les levées d'hommes. Il est certain que l'armée était grosse consommatrice de grains, de chevaux... et d'hommes. Comment faire face aux travaux des champs quand le cheptel vif est ainsi confisqué ? Comment affronter la mainmise sur les stocks ? Comment surmonter le manque de main-d'œuvre? Encore ne disons-nous rien des destructions endurées par les fermes dans les zones de combat. Il est certain que certaines exploitations ont vécu des moments difficiles. Comment renouveler le cheptel, comment travailler avec moins de chevaux, enfin comment acquitter des salaires poussés à la hausse par la rareté de la maind'œuvre?

Sur le plan salarial, les détracteurs de la Révolution se placent en effet à nouveau dans une position avantageuse. Soit les salaires sont considérés comme stagnants, voire en retard, et dans ce cas on montrera que les journaliers n'ont profité en rien de la Révolution, soit ils sont en progression et dans ce cas c'est l'employeur qui est confronté à une montée en flèche de ses coûts de production qui le pénalise durement. Qu'en est-il vraiment?

Les salariés durent bénéficier de la nouvelle conjoncture. Moins nombreux en raison des levées d'hommes, moins demandeurs d'emplois puisqu'un certain nombre d'entre eux avaient grappillé des lopins en profitant des ventes de biens nationaux ou des partages de biens communaux, ils pouvaient revendiquer des salaires en hausse ${ }^{66}$. La tension sur les salaires, surtout dans le climat de l'an II, en effet, s'accentua. Pour mieux comprendre ce qui s'est réellement passé, là encore il convient de se replacer dans la moyenne durée. Longtemps à la traîne par rapport aux prix, les salaires avaient commencé à se redresser à la veille de la

(65) Gilles Postel-VInAY, «À la recherche de la révolution économique dans les campagnes (1789-1815) », Revue économique, 40-6, novembre 1989, p. 1015-1045.

(66) Ibid. 
Révolution ${ }^{67}$. Tous les indices concordent. La Révolution se situe en plein dans cette phase provisoirement plus favorable aux salariés ${ }^{68}$. Le Maximum et plus largement l'encadrement quelque peu prolongé du marché des grains les protégèrent, au moins à titre transitoire, dans la mesure où leurs revenus suivirent sans peine le mouvement des prix malgré le frein que constitua le Maximum des salaires ${ }^{69}$.

Bien évidemment, il faudrait envisager le mouvement du profit des éleveurs, des vignerons et des autres catégories sociales. On ne le fera pas ici faute de place et d'information fiable. On a dit que les journaliers ne vécurent probablement pas les pires moments de leur existence et qu'ils profitèrent des conditions ambiantes pendant un temps assez long. Faut-il pour autant pleurer sur le sort des fermiers ? Victimes de la conjoncture céréalière, notamment lors de deux crises terribles, malmenés par les réquisitions, pénalisés par le mouvement des salaires, privés d'un volant de récolte qui autorisait toutes les spéculations, handicapés par une rente qui résiste, comment ont-ils pu passer l'orage? Apparemment très bien, si l'on en juge par l'insolente prospérité de ces « notables consolidés $»^{70}$. À l'issue d'une décennie certes délicate à négocier, on trouvera peu de raisons de se lamenter longuement sur leurs malheurs. Apparemment ils avaient su négocier ce virage et trouver d'heureuses compensations.

\section{La dette. La détresse des créanciers?}

L'un des effets indirects de la Révolution fut le formidable transfert qui se produisit au détriment des créanciers et au profit des débiteurs. Le

(67) Ernest Labrousse, Esquisse du mouvement des prix et des revenus en France au XVIII siècle, Paris, Librairie Dalloz, 1933, rééd. Paris-Montreux, Gordon and Breach Science Publishers, 1984, p. 490-493. Abel Poitrineau, La vie rurale en Basse-Auvergne..., op. cit., p. 496-499 ; JeanPierre Poussou, Bordeaux et le Sud-Ouest au XVIII siècle. Croissance économique et attraction urbaine, Paris, EHESS et Jean Touzot, 1983, p. 329-330 ; Georges FrÊCHE, Toulouse et la région Midi-Pyrénées au siècle des Lumières. Vers 1670-1789, Paris, Cujas, 1974, p. 562.

(68) David R. WeIR, «Les crises économiques et les origines de la Révolution française », Annales ESC, 46-4, 1991, p. 917-947.

(69) Gilles Postel-Vinay dans Gérard Béaur, Philippe Minard et Alexandra Laclau (éd.), Atlas..., op. cit., p. 70 ; Yvonne CREBOuw, «Les salariés agricoles face au Maximum des salaires », dans La Révolution française et le monde rural, op. cit., p. 113-122 ; Dominique MARGaIRAz, « Le maximum, politique économique ou politique sociale ? », dans Jean-Pierre Jessenne, Gilles DereGNAUCOURT (éd.), Robespierre : de la nation artésienne à la République des nations, Villeneuve d'Ascq, CHRN-Université Lille 3, 1994, p. 263-278.

(70) Jean-Marc Moriceau, « Des notables consolidés ? Les “ propriétaires-cultivateurs ” au lendemain de la Révolution », dans Les Paysans et la Révolution en Pays de France. Actes du colloque de Tremblay-en-France (15-16 octobre 1988), Mitry, Association pour le Bicentenaire de la Révolution, 1989 , p. 215-236. 
responsable de ce bouleversement du système de crédit est évidemment l'assignat. Sa dépréciation provoqua en effet la ruée des emprunteurs bien décidés à se libérer à bon compte. Des scènes pathétiques, presque cocasses, ont été décrites dans les rares documents publiés par les historiens $^{71}$. Les créanciers refusent d'ouvrir leur porte, font dire par leur femme qu'ils sont absents ou trop malades, font le coup de poing pour refouler les débiteurs acharnés à rembourser ce qu'ils doivent, parfois depuis fort longtemps. Ceux-ci viennent accompagnés d'un huissier et déposent de force l'argent sur la table pour attester qu'ils ne doivent plus rien. Tout y passe. Les vieilles dettes contractées pour acheter de la terre ou pour passer un moment difficile, les dots non acquittées, les indemnisations des co-héritiers, le règlement des baux à cheptel pour s'acquitter du paiement des bestiaux engagés par les preneurs et bien sûr les annuités des achats de biens nationaux.

Face à ce déchaînement, les créanciers sont sans défense. Ils essaient d'exiger des paiements en nature ou en monnaie métallique mais c'est généralement peine perdue. L'obstination des débiteurs résulte exclusivement de la perspective alléchante de se libérer de manière indolore. Ce n'est que tardivement que le gouvernement prend la mesure du phénomène et adopte les premières mesures destinées à préserver les intérêts des créanciers. Le 23 messidor an III, il interdit de rembourser en assignats les fonds avancés avant le $1^{\text {er }}$ janvier 1792 et de rembourser les autres par anticipation. Peu après, il établit une double, puis une triple comptabilité (avec les mandats territoriaux) pour percevoir les impôts type enregistrement en fonction de la monnaie employée dans la transaction. Les tableaux de dépréciation de l'assignat permettent de freiner le mouvement, non de l'arrêter totalement. On peut suivre à Chartres l'évolution des amortissements de rentes pendant la Révolution française ${ }^{72}$. On retrouve le même calendrier à Bar-sur-Seine (en Champagne) et à Privas (dans le Vivarais) $^{73}$.

Le pic se situe en l'an II, et surtout en l'an III, c'est-à-dire au moment où la dépréciation est maximale et où il est possible de jouer sur « le taux de change ». Autrement dit, les bénéficiaires de ce coup de

(71) Pierre Massé, « À travers un dépôt de minutes notariales », Annales historiques de la Révolution française, XXV, 2, 1953, p. 297-315.

(72) Daniel Roche, Michel Vovelle, « Bourgeois, rentiers, propriétaires : éléments pour la définition d'une catégorie sociale à la fin du XVIII ${ }^{\mathrm{e}}$ siècle ", dans Actes du $84^{\mathrm{e}}$ Congrès national des Sociétés Savantes (Dijon, 1959), Paris, 1960, p. 419-453, rééd. dans Ville et campagne au XVIII siècle, op. cit., p. 137-166.

(73) Gilles Postel-Vinay, La terre et l'argent..., op. cit., p. 141-144. 
chance ont su choisir leur moment. Beaucoup de ceux qui avaient des liquidités ont attendu l'instant favorable, ni trop tôt, pas avant que la chute ne soit suffisante, ni trop tard, pas après que le remboursement ne pouvait se faire dans des conditions favorables. Quelle est la portée de cette redistribution? Gilles Postel-Vinay n'hésite pas à avancer le chiffre de 5 à $10 \%$ de la valeur des terres, autrement dit l'équivalent des ventes de biens nationaux. Il postule une sorte de remise à zéro des compteurs du crédit qui soulage les emprunteurs mais ruine les prêteurs ${ }^{74}$. Le bilan est assez facile à établir. À partir du moment où les campagnes étaient nettement débitrices à l'égard des villes, il est clair que les ruraux sont les grands bénéficiaires de ce formidable transport, au moins dans un premier temps.

En réalité, c'est tout le système de crédit qui se trouve ainsi remis en cause et au bord de l'asphyxie. C'est quasiment l'acte de décès des prêts à long terme, des rentes non plus perpétuelles mais pour une durée de plusieurs années. Seuls subsistent les prêts à court terme, en particulier les obligations. Cette évolution prolonge d'une certaine manière celle de l'Ancien Régime qui laissait déjà voir un déclin lent mais irrésistible des engagements de longue durée au profit des prêts plus courts $^{75}$. Si l'encours global était en progression très nette au cours du demi-siècle qui précède la chute de l'Ancien Régime, il s'effondre à partir de l'an IV. Dès 1796, les campagnes ont soif de liquidités. En effet, les détenteurs de monnaie, échaudés par ce coup du sort, y regardent dorénavant à deux fois avant de délivrer leur précieux numéraire. Ils exigent des garanties plus fortes, ne s'engagent que pour des temps plus brefs, 1 an au maximum, et revendiquent des taux d'intérêt élevés. Sous le Consulat, on estime que les taux oscillent entre 10 et $15 \%$, soit 2 à 3 fois les niveaux atteints avant la Révolution, avec des zones de basse pression dans le Nord et dans l'Est (6-8 \% en Alsace) et des zones nettement plus défavorisées où le taux normal peut atteindre les $25 \%$ dans les Pyrénées ou le Massif Central, et tout cela sans préjudice de l'usure qui sévit dans les campagnes ${ }^{76}$.

Pourtant, ce désarroi ne fut que transitoire. Le système de crédit se reconstitue peu à peu, à mesure que la confiance revient ou que les besoins croissent $^{77}$. La création d'une formalité hypothécaire, plus solide, sur les

(77) Jean-Jacques CLĖre, Les paysans de la Haute-Marne..., op. cit., p. 348-354. 
bases de ce qu'avait essayé d'instaurer l'Ancien Régime en 1771 et qui avait été liquidé en 1795, après 5 ans de lente agonie, permet de garantir les prêts sur la terre. En 1820, le stock de prêts a grosso modo retrouvé son niveau de 1789 dans certaines régions (Bar-sur-Seine), mais pas dans d'autres (Rugles en Normandie) ${ }^{78}$. Comment interpréter cette restauration ? Un symptôme des difficultés récurrentes du monde rural ? Une restauration des flux qui préexistaient? Une vague d'investissement ? Et comment interpréter la lenteur du redémarrage ? Une paysannerie durablement soulagée et libérée de ses dettes, ou l'incapacité de trouver des prêteurs?

\section{L'héritage. La victoire des cadets?}

Le Code civil a souvent été vilipendé pour des méfaits largement imaginaires. En assurant l'égalité entre tous les héritiers, il serait la cause du morcellement des héritages et de la désagrégation des propriétés. Le Code civil serait la « machine à hacher le sol ». Cette interprétation est fort exagérée, pour ne pas dire fantaisiste. En effet, les héritages étaient déjà partagés entre tous les enfants dans une bonne partie de la France, et de manière égalitaire ${ }^{79}$. La France était déjà un pays de petits propriétaires.

Il est cependant vrai que dans d'autres régions, en particulier le Midi de la France, du Massif Central aux Pyrénées, mais aussi dans le Pays de Caux, un seul héritier prenait la succession du père, généralement mais pas obligatoirement l'aîné, tandis que les frères et sœurs étaient désintéressés par le versement d'une légitime, quand elle était payée ${ }^{80}$. Dans d'autres provinces, telle la Normandie (hors Pays de Caux), les filles étaient exclues, dotées, et seuls les garçons héritaient. Mais les situations

(78) Gilles Postel-Vinay, La terre et l'argent..., op. cit., p. 147-150.

(79) Jean Yver, Essai de géographie coutumière. Égalité entre héritiers et exclusion des enfants dotés, Paris, Sirey, 1966 ; Emmanuel Le Roy Ladurie, "Système de la coutume. Structures familiales et coutumes d'héritage en France au XVI ${ }^{\mathrm{e}}$ siècle », Annales ESC, 27-4/5, 1972, p. $825-846$.

(80) Cf. notamment les articles de Rolande Bonnain, Antoinette Fauve-Chamoux, dans Isaac Chiva, Joseph Goy, (dir.), Les Baronnies des Pyrénées. Anthropologie et histoire, permanences et changements, t. 1, Maisons, Mode de vie, Société, Paris, Éditions de 1'EHESS, 1981, et t. II Maisons, Espaces, Familles, Paris, Éditions de l'EHESS, 1985 ; Rolande BonnaIn, Gérard Bouchard, Joseph Goy (éd.), Transmettre, hériter, succéder. La reproduction familiale en milieu rural, FranceQuébec, XVIII ${ }^{e}$ XIX $X^{e}$ siècles, Lyon-Paris-Villeurbanne, Presses Universitaires de Lyon, 1992 ; Gérard Bouchard, Joseph Goy, Anne-Lise Head-König (éd.), Problèmes de la transmission des exploitations agricoles $\left(X V I I I^{e}-X X^{e}\right.$ siècles). Nécessités économiques et pratiques juridiques, Rome, École Française de Rome, 1998. 
étaient finalement assez disparates, puisque tout était réglé par la coutume, surtout au Nord, et puisque cette coutume était assez différente d'une zone à l'autre.

Dès avril 1791, la Constituante, décidée à promouvoir un modèle d'héritage unique, proclama l'égalité entre tous les héritiers en l'absence de testament, puis le 7 mars 1793, la Convention abolit le droit d'avantager l'un des héritiers par contrat de mariage ou par testament, instituant ainsi une égalité totale entre tous les héritiers. Bien plus, elle décide en nivôse an II d'annuler les actes passés depuis le 14 juillet 1789 qui contrevenait à ce principe d'égalité. Il fallut revenir sur cette dernière mesure rétroactive tant il apparut qu'elle provoquait un beau désordre. Après bien des repentirs, le Code civil, ce « compromis génial », ce « bricolage idéologique », aboutit à un compromis en confirmant l'égalité entre tous les héritiers mais en accordant aux familles la possibilité de disposer à leur gré d'une quotité pour avantager un successeur ${ }^{81}$.

Quels furent les effets de cette réforme en plusieurs temps ? Dans la plus grande partie de la France, ils furent nuls puisque le nouveau système ne changeait strictement rien. En Normandie, il semble bien que les familles aient aisément intégré les nouvelles dispositions qui leur étaient proposées et au moins dans la région de Vernon, il est vrai limitrophe des régions égalitaires, qu'elles aient rapidement adopté le partage au profit des filles comme des garçons ${ }^{82}$. Était-ce le cas dans la Normandie profonde ? On l'ignore. Mais dans les zones de transmission à un seul héritier, les résistances furent vives. Une série de parades furent imaginées pour tourner la loi et empêcher les cadets d'obtenir leur part d'héritage. Ventes fictives, reconnaissances de dettes factices, sous-évaluations, tout est bon, pour maintenir le modèle de l'héritier unique ${ }^{83}$. Il est exact que de nombreux cadets ne remettent guère en cause leur spoliation et ne revendiquent pas ce à quoi ils peuvent prétendre. À la rigueur, ils réclament un supplément de légitime. Lorsqu'on examine la situation en 1810 et même bien plus tard, on se rend compte que les anciennes pratiques ont résisté et que l'on retrouve des départements où le contrat de mariage ou le testament restent des moyens communément employés pour « faire un héritier », et

(81) Joseph Goy, «Transmission successorale et paysannerie pendant la Révolution française : un grand malentendu », Études rurales, 110-112, 1988, p. 45-56.

(82) Fabrice BoudjaAba, La circulation des biens-fonds..., thèse cit., p. 408.

(83) Rolande Bonnain, « Le mariage dans les Pyrénées centrales, 1789-1836 », dans Isaac Chiva, Joseph Goy (dir.), Les Baronnies des Pyrénées, op. cit., t. II, p. 123-156. 
des départements où l'on continue systématiquement d'éviter de recourir à de tels actes ${ }^{84}$.

Rien n'est donc changé ? Il semblerait que l'on ait exagéré la vigueur du refus. De nombreuses familles ont rapidement assimilé les nouveaux principes édictés par les révolutionnaires et ont entrepris d'effectuer de véritables partages. C'est le cas dans le Béarn. Dans cette région, les familles ont rapidement tenu compte des facilités et des contraintes que leur imposait le Code. Elles ont instauré des partages quitte à jouer sur la quotité disponible comme les y incitait le Code ou à jouer sur les flux d'héritage collatéraux pour avantager l'un des héritiers ${ }^{85}$. Partout, l'héritier unique est en perte de vitesse. À Augerolles, dans le Livradois (Massif Central), il est fréquemment remplacé par un héritier doté d'un préciput, chargé d'indemniser plus ou moins bien ses co-héritiers $^{86}$. De toute manière, dans les Pyrénées, pour lesquelles on dispose d'un lot d'informations précises, les cadets n'hésitent plus à se marier en épousant des cadettes. À Esparros, la proportion de mariages cadets/ cadettes double, passant de 22 à $47 \%$. Ils n'hésitent plus à exiger des compensations financières. Ils créent de nouvelles « maisons » en mobilisant les parcelles concédées par les familles ou en colonisant pâturages et terres communales pour y fonder des exploitations. En escaladant les pentes et en mettant en culture des terres de moindre qualité, ces cadets n'ont pas forcément la partie belle et beaucoup échouent, sauf à revenir au partage inégalitaire à la génération suivante pour sauver leur exploitation $^{87}$.

En réalité, ce changement à l'égard des cadets n'est pas sorti tout droit, brutalement, de la Révolution. C'est avant la Révolution, dès le $\mathrm{XVIII}^{\mathrm{e}}$ siècle, dans les Pyrénées, que les cadets entreprennent de s'installer

(84) Gérard BÉAUR, « Le secours de la méthode. Comment les familles transmettaient leurs biens et excluaient leurs enfants dans la France du début du $19^{\mathrm{e}}$ siècle », dans Gérard BÉAuR, Christian Dessureault, Joseph Goy (dir.), Familles, Terre, Marchés. Logiques économiques et stratégies dans les milieux ruraux (XVII $-X X^{e}$ siècles), Rennes, Presses universitaires de Rennes, 2004, p. 121-131.

(85) Christine Lacanette-Pommel, La famille dans les Pyrénées. De la coutume au Code Napoléon, s.1., Universatim PyréGraph, 2003.

(86) Bernard Brunel, Le vouloir vivre et la force des choses. Augerolles en Livradois-Forez $d u X V I I^{e}$ au XIX siècle, Clermont-Ferrand, Université Blaise-Pascal, Institut d'études du Massif Central, 1992, p. 316-317.

(87) Notamment Antoinette FAUVE-CHAMOUX, « La reproduction familiale en milieu paysan : le destin des exclus », dans Gérard Bouchard, John Dickinson, Joseph Goy (dir.), Les exclus de la terre en France et au Québec, XVII ${ }^{e}$-XX $X^{e}$ siècles, Montréal, Septentrion, 1998, p. 73-92 et « Les frontières de l'autorégulation paysanne : croissance et famille-souche », Revue de la Bibliothèque nationale, 50, hiver 1993, p. 38-47. 
dans des conditions précaires, plutôt que de rester célibataires/domestiques sur l'exploitation de l'aîné ou de s'expatrier, même si, bien entendu, le phénomène explose avec les réformes introduites par le nouveau régime $^{88}$. C'est bien avant la Révolution, dans le Val de Saône, que le partage égalitaire est instauré entre tous les héritiers. La différence, c'est que le partage devient effectif et ne reste pas virtuel, contrecarré par le maintien dans l'indivision, comme c'était le cas auparavant. Les lois révolutionnaires n'y sont pour rien en l'occurrence. La disparition de la tutelle seigneuriale qui laissait planer une menace sur les lots individuels semble bien davantage responsable ${ }^{89}$. Ainsi, partout où il préexistait, le vieux système inégalitaire se maintint mais fut largement altéré par le vent qui soufflait sur les familles à la fin de l'Ancien Régime. Des ferments d'égalité avaient levé, même si la victoire des cadets demeura incomplète.

Trois faits majeurs sont apparus avec la force de l'évidence. Un : les formidables distorsions régionales produites par des réformes qui affectent plus ou moins certaines régions, certaines paroisses, certaines familles. Les inégalités de traitement qui leur étaient infligées avant la Révolution expliquent que lorsque tout change, ils en tirent plus ou moins d'avantages et bénéficient plus ou moins de la redistribution effectuée. Deux : le temps modifie les jugements que l'on peut porter sur les bénéfices obtenus par chacun. La conjoncture pèse ici d'un poids très lourd et la guerre encore plus. C'est cette dernière qui déséquilibre les positions des agents économiques, en même temps que la monnaie-papier introduit des aléas imprévus. Trois : les changements observés ont des effets différentiels sur les catégories d'acteurs. "Les Français ont d'abord gagné comme contribuables en 1790-91 [on ajoutera jusqu'en 1798 au moins] ; puis, ils ont perdu comme producteurs et comme marchands en 1792-94; enfin, depuis l'abolition du maximum ils subissent l'explosion des prix comme consommateurs [sans doute faudrait-il nuancer à la campagne] », dit Jean-Claude Perrot ${ }^{90}$. Le problème, c'est que chaque Français, et pour ce qui nous occupe, chaque habitant des campagnes, décline plusieurs

(88) Ibid.

(89) Philippe Gonod, Propriété et partage du sol. La transmission du patrimoine dans le Val de Saône aux XVIII et XIX siècles, thèse Université de Lyon 2, 1993, p. 229.

(90) Jean-Claude Perrot, « Capitalisme, finances publiques et Révolution », dans Gérard GAYOT, Jean-Pierre Hirsch (éd.), La Révolution française et le développement du capitalisme, (actes du colloque de Lille, 1987), Villeneuve d'Ascq, Collection Hors Série de la Revue du Nord, 1989, p. 17-26. 
postures. L'éventail des configurations possibles est infini. Chacun se positionne par rapport à l'impôt, au foncier, à la rente, à la dette, au prélèvement seigneurial, et donc obtient des gains plus ou moins forts, voire des pertes, dans chaque compartiment. Il doit être clair que la Révolution s'est montrée plus clémente envers les débiteurs, les cadets, les journaliers, les laboureurs, les tenanciers, qu'envers les créanciers, les aînés, les rentiers, les seigneurs ou les membres du clergé.

Reste à savoir si la redistribution s'est opérée à périmètre constant, aux dépens d'autres agents économiques pénalisés par l'évolution économique ou les changements institutionnels, ou bien si le gâteau à partager a en même temps changé de volume. Dans la deuxième hypothèse, selon que l'on considérera que la Révolution française fut une catastrophe ou l'amorce d'un essor économique, on admettra que les campagnes ont prospéré contre le reste du pays ou avec lui. Quoi qu'il en soit, globalement, on dira que les campagnes ont été plutôt bénéficiaires. Tous les indicateurs suggèrent que la paysannerie semble bien être sortie renforcée de l'épreuve. Distinguons. La petite paysannerie récupéra certes des miettes mais n'en profita pas moins de l'attribution de quelques précieux lopins par différentes voies, de l'avilissement des créances, de la chute des prélèvements. Les gros exploitants furent encore plus chanceux puisqu'ils virent disparaître les charges seigneuriales, les dîmes, diminuer les charges fiscales, et qu'ils profitèrent aussi bien des transferts fonciers ouverts par les ventes de biens nationaux que des opportunités offertes par le marché.

Les transferts induits par la Révolution furent finalement beaucoup plus larges qu'un examen superficiel n'incite à la croire. L'événement a engendré une énorme redistribution des revenus et des patrimoines. À côté des transferts bien repérables et largement soulignés par les historiens, il en est d'autres, moins spectaculaires, quasiment invisibles, mais tout aussi efficaces, qui méritent d'être désormais explorés avec assiduité après qu'on les avait longtemps négligés.

Gérard BÉAUR

Centre de Recherches Historiques,

CNRS-EHESS, 54 boulevard Raspail 75006 Paris 